\title{
OS MOVIMENTOS SOCIAIS PARA APROPRIAÇÃO E CONSOLIDAÇÃO DO ESPAÇO DE LAZER E CULTURA “ZUMBI DOS PALMARES” LOCALIZADO EM TERESINA-PI ${ }^{1}$
}

Recebido em: 05/03/2018

Aceito em: 27/10/2018

Edvaldo Cesar da S. Oliveira

Luiz Carlos Soares Santos ${ }^{3}$

Instituto Federal de Ciência e Tecnologia do Piauí (IFPI)

Teresina - PI - Brasil

João Batista Lopes da Silva ${ }^{4}$ Universidade do Estado de Mato Grosso/UNEMAT - Campus Sinop Sinop - MT - Brasil

Luis Otavio T. Assumpção ${ }^{5}$ Universidade Católica de Brasília

Brasília - DF - Brasil

RESUMO: Analisamos o processo de apropriação e consolidação do espaço de lazer e cultura "Zumbi dos Palmares", localizado em Teresina, capital do estado do Piauí. Destacamos e analisamos conflitos, lutas e movimentos realizados com o intuito de se apropriar deste espaço, antes de natureza escolar, hoje destinado a atividades de lazer, particularmente de diversas manifestações da cultura negra (coral em yorubá, oficinas de capoeira, percussão, dança, festas temáticas, cinema, biblioteca, exposições, etc). Atualmente a apropriação e consolidação deste espaço exerce um importante papel na difusão e valorização desta cultura no Piauí. A pesquisa foi realizada sob uma perspectiva qualitativa descritiva, tendo sido utilizada a entrevista semiestruturada como principal técnica de coleta de dados.

\footnotetext{
${ }^{1}$ Artigo premiado no $29^{\circ}$ Encontro Nacional de Recreação e Lazer (ENAREL), realizado em Caruaru/PE em 2017.

${ }^{2}$ Graduado em Educação Física pela Universidade Federal do Piauí-UFPI. Esp. em docência do ensino superior pela Faculdade Santo Agostinho-FSA. Mestre em Educação Física pela Universidade Católica de Brasília. Doutorando em Educação física pela Universidade Católica de Brasília. Professor vinculado ao Instituto Federal de Ciência e Tecnologia do Piauí-IFPI.

${ }^{3}$ Graduado em Educação Física pela Universidade Federal do Piauí-UFPI. Especialista em Educação Física pela Pontifícia Universidade Católica de Belo Horizonte/PUC Minas. Mestre em Educação Física pela Universidade Católica de Brasília. Doutorando em Educação Física pela Universidade Católica de Brasília. Professor do Instituto Federal de Ciência e Tecnologia do Piauí-IFPI.

${ }^{4}$ Graduado em Educação Física-UNICRUZ/RS. Mestre em Ciências da Educação-Universidade de Cienfuegos/Cuba. Doutorando em Educação Física pela UCB/DF. Professor da Universidade do Estado de Mato Grosso/UNEMAT, Campus Sinop.

5 Bacharel, Mestre e Doutor em Sociologia pela Universidade de Brasília. Professor adjunto da Universidade Católica de Brasília. Professor-orientador do Mestrado e Doutorado em Educação Física da Universidade Católica de Brasília.
} 
Edvaldo Cesar da S. Oliveira, Os Movimentos Sociais para Apropriação e Consolidação do Espaço... Luiz Carlos Soares Santos, João Batista Lopes da Silva e

Luis Otavio T. Assumpção

PALAVRAS CHAVE: Grupo com Ancestrais do Continente Africano. Negro. Atividades de Lazer. Identidade.

\section{THE SOCIAL MOVEMENTS FOR THE APPROPRIATION AND CONSOLIDATION OF THE LEISURE AND CULTURE SPACE "ZUMBI DOS PALMARES" LOCATED IN TERESINA-PI}

ABSTRAT: We analyse the appropriation and consolidation process of the leisure and cultural place called 'Zumbi dos Palmares' located in Teresina, capital of the State of Piaui. We pointed out and analyse some conflicts, struggles and movements which were made in order to appropriate this place, which it was once a school environment, nowadays it is a place intended for leisure activities, specially several manifestations of the black culture (Choir in Yorubá, Capoeira workshops, percussion, dancing, theme parties, cinema, library, expositions and so on). Nowadays the appropriation and consolidation of the place has an important role in spreading and valuating such culture in Piaui. This research was carried out from a qualitative and descriptive perspective, and made use of a semi structured interview as the main technique of data collecting.

KEYWORDS: African Continental Ancestry Group. Black. Leisure Activities. Identity.

\section{Introdução}

\section{Caracterização do espaço}

Na cidade de Teresina, capital do estado do Piauí, há um importante espaço de lazer destinado à divulgação, aglutinação e exercício da cultura negra, um local onde se possa reunir e se expressar os mais diversos segmentos da sociedade negra.

Trata-se de um imóvel urbano pertencente ao patrimônio imobiliário estadual, (onde antes funcionava a Unidade Escolar Domingos Jorge Velho) - o Memorial “Zumbi dos Palmares, subordinado à Secretaria Estadual de Cultura (SECULT), o qual foi fundado como reconhecimento do povo piauiense à contribuição social e cultural da etnia negra”.

A transformação dos desígnios de uma unidade escolar em Memorial de atividades de lazer e cultural resultou de um longo e conflituoso processo social, 
Edvaldo Cesar da S. Oliveira, Os Movimentos Sociais para Apropriação e Consolidação do Espaço... Luiz Carlos Soares Santos, João Batista Lopes da Silva e

Luis Otavio T. Assumpção

envolvendo importantes atores políticos, movimentos sociais, ampla pressão social e elaboradas articulações até sua conquista definitiva. Exerceram papel de destaque os movimentos negros organizados, em particular os Grupos afros "Coisa de Negro", "Movimento Negro Unificado", "Ifaradá" - Núcleo de pesquisa africanidade e afrodescendências, Coletivo de Mulheres Negras "Esperança Garcia" e alguns intelectuais afrodescendentes e não afrodescendentes do Piauí.

O marco oficial de sua criação se deu pelo Decreto-Lei no 5.311 , de 12/03/2003, com a finalidade de "conscientizar e sensibilizar a sociedade de que o Piauí procura respeitar a diversidade cultural, religiosa, racial e de gênero, e, com isso, garantir os plenos direitos e deveres de todos" (PPP, 2010, p. 01). Reza o Art.1": "fica criado o Memorial Zumbi dos Palmares, a ser instalado na cidade de Teresina, no imóvel urbano pertencente ao patrimônio imobiliário estadual, onde funcionou a Unidade Escolar Domingos Jorge Velho, como tributo e reconhecimento do povo piauiense à efetiva contribuição negra no processo histórico brasileiro" (BRASIL, 2003, p. 230).

Este espaço tem uma significação social, cultural e simbólica bastante significativa. Com ele, há um reconhecimento legal do poder público da efetiva contribuição da população afrodescendente no estado do Piauí, bem como a garantia de um espaço de lazer, resistência e valorização da cultura negra nas suas diversas manifestações.

O Memorial Zumbi dos Palmares, dissemos, foi resultado de um amplo processo de movimentação social. Trataremos deste elemento analítico para melhor se compreender este processo de luta pela apropriação de espaços, tanto urbanos como rurais. 
Edvaldo Cesar da S. Oliveira, Os Movimentos Sociais para Apropriação e Consolidação do Espaço... Luiz Carlos Soares Santos, João Batista Lopes da Silva e

Luis Otavio T. Assumpção

\section{Movimentos Sociais}

Historicamente, em processos dessa natureza, os movimentos sociais têm desempenhado um importante e efetivo papel.

Movimentos sociais, segundo Blumer (1976), podem ser considerados como empreendimentos coletivos para estabelecimento de uma nova configuração de vida. São fruto de uma inquietação social, derivando de uma insatisfação sobre alguma questão relacionada a sua própria vida e dos demais membros de uma sociedade.

Para Gohn (2010, p.20) em seus diferentes estudos sobre movimentos sociais, caracteriza-os como "ações sociopolíticas construídas por atores coletivos de diferentes classes sociais, numa conjuntura específica de relações de força na sociedade civil”.

No entendimento de Bobbio (1998, p.5), citando Alain Touraine, "os movimentos sociais pertencem aos processos pelos quais uma sociedade cria a sua organização, a partir do seu sistema de ação histórica, através dos conflitos de classe e dos acordos políticos"

Quando as pessoas articulam e desenvolvem visões e práticas do que acreditam serem seus direitos, como no caso da luta pela apropriação do Memorial Zumbi dos Palmares, cresce a possibilidade do surgimento de novos valores e, com eles, amadurecerem inquietações por mudanças. "O desenvolvimento dos novos valores produzidos por essas tendências culturais implica interessantes mudanças psíquicas que fornecem a motivação para os movimentos sociais gerais" (BLUMER, 1976, p. 80).

Entendemos que, em processos formativos dos movimentos sociais, as pessoas, mesmo que embrionariamente, começam a formar novas concepções de si próprias, não condizentes com as antigas crenças e posições. Surgem, então, novos questionamentos que precisam ser resolvidos. 
Edvaldo Cesar da S. Oliveira, Os Movimentos Sociais para Apropriação e Consolidação do Espaço... Luiz Carlos Soares Santos, João Batista Lopes da Silva e

Luis Otavio T. Assumpção

No caso desta pesquisa refletimos sobre este processo entre a população negra de Teresina em sua luta pelo Memorial citado.

Em função de sua complexidade, naturalmente a temática de movimentos sociais não possui uma unidade teórico-conceitual, "não é consensual nas ciências sociais" (PICOLOTTO, 2007, p.2).

No tocante à polarização de concepções há o que se denomina "modelo clássico (europeu), que privilegia as interpretações históricas das revoluções e uma interpretação norte-americana, que valoriza a organização e mobilização de recursos por atores sociais" (PICOLOTTO, 2007, p.10). Nosso trabalho mais se aproxima da segunda linha.

Existem diferentes movimentos sociais. Alguns estão baseados na defesa de certas ideias até certo ponto perigosas (xenofóbicas, nacionalistas, religiosas) construídos com práticas sectárias, destrutivas e de negação da ordem aceita vigente. Outros, mais progressistas, atuam segundo uma ordem emancipatória realizando diagnósticos sobre a realidade social.

De um lado estão os que se preocupam com a irrupção das massas na cena política e veem nos comportamentos coletivos uma manifestação de irracionalidade, um rompimento perigoso da ordem existente. De outro lado estão os que veem nos movimentos coletivos um modo peculiar de ação social, variavelmente inserida ou capaz de se inserir na estrutura global (BOBBIO, 1998).

Os movimentos sociais podem ser classificados como gerais e/ou específicos. Gerais correspondem a um tipo de movimento que toma a forma de esforços tateantes e descoordenados, possuindo apenas "uma orientação geral no sentido da qual se processam de maneira vagarosa, hesitante, mas persistente”. São pouco organizados, 
Edvaldo Cesar da S. Oliveira, Os Movimentos Sociais para Apropriação e Consolidação do Espaço... Luiz Carlos Soares Santos, João Batista Lopes da Silva e

Luis Otavio T. Assumpção

sem lideranças estabelecidas nem reconhecimento da participação de seus membros, e apresentam pouca direção e controle (BLUMER, 1976, p. 80).

Como todo movimento social geral operam num amplo âmbito: lar, educação, política, em todas as áreas que se busque ordenação; pode apresentar considerável entusiasmo num ponto, e relutância e inércia em outro; pode ter êxito num setor e constituir um esforço infrutífero em outro.

Os líderes, nos movimentos sociais gerais desempenham papel importante, não por exercerem poder diretivo tomando decisões importantes e necessárias para o desenvolvimento das estratégias necessárias para o sucesso dos mesmos mas por encaminharem e darem continuidade aos possíveis desdobramentos conseguidos assumindo a ação em diferentes pontos referentes ao mesmo. "Esses líderes frequentemente estão não muito conscientes de seus próprios objetivos. Contudo, seu exemplo ajuda a sensibilidade, desperta esperança e solapa resistências" (BLUMER,1976, p. 81).

O movimento social geral é dominado, em larga escala, pelos mecanismos de comportamentos de massa, sendo bastante amorfos na organização e inarticulados na expressão, oferecendo alicerces para os movimentos sociais específicos, que irão converter as insatisfações de caráter geral em objetivos específicos.

Os movimentos sociais específicos são aqueles que "possuem algum direcionamento, e objetivo bastante preciso e específico, que precisa ser alcançado e desejado". Sendo assim, seu esforço e organização desenvolve uma estrutura que os tornam essenciais em uma sociedade (BLUMER, 1976, p. 82). Nosso caso de estudo guarda elementos desse caráter específico. 
Edvaldo Cesar da S. Oliveira, Os Movimentos Sociais para Apropriação e Consolidação do Espaço... Luiz Carlos Soares Santos, João Batista Lopes da Silva e

Luis Otavio T. Assumpção

Outro importante elemento teórico nos estudos sobre movimentos sociais referese ao papel e à ação individual, elemento que, segundo Morris (2000), ocorre de maneira um tanto turva nas teorias relacionadas ao tema. Os movimentos são vistos como resultado de oportunidades políticas, de recursos disponíveis e mesmo de movimentos históricos que opõem classes sociais. No entanto, deve-se estar atento para o papel dos indivíduos, pois, são eles, em última instância - e não as estruturas - que deliberam, imaginam, criam estratégias ou tomam decisões. Nisto, há o agenciamento do ator humano que, interagindo no interior das estruturas sociais, realizam essas atividades, exercendo papéis significativos. Nesse estudo destacamos o papel de nossos entrevistados como importantes atores neste processo.

Para Dawson e Gettys,1989; Blumer,1976 movimentos sociais são divididos em quatro fases ou etapas descritas por (a) inquietação social,(as pessoas agem desordenadamente, estão inquietas por uma situação, ansiosas, aqui o líder é um agitador com papel importante, o comportamento desordenado e errático é significativo); (b) excitação popular (emergem noções mais definidas quanto a condição da pessoa e o que deve ser feito para mudança social, o líder tende a ser um reformador), (c) formalização (organizado com regras política, táticas e disciplina o líder tende a ser um homem de Estado); (d) institucionalização (organização fixa, com pessoal e estrutura definidos, o líder tende a ser um administrador). Nos limites desse artigo não podemos explorar suficientemente estas quatro dimensões mas indicamos sua presença e importância para maior clareza desse processo.

Em estudos sobre movimentos sociais, não se pode deixar de fazer referência à significativa contribuição do sociólogo francês Alain Touraine (1977). Em sua teoria sobre o tema, ele apresenta o conceito de movimento social como uma complexa 
Edvaldo Cesar da S. Oliveira, Os Movimentos Sociais para Apropriação e Consolidação do Espaço... Luiz Carlos Soares Santos, João Batista Lopes da Silva e

Luis Otavio T. Assumpção

combinação de três princípios: um princípio de identidade - na definição do ator por ele mesmo; um princípio de oposição - quando o ator identifica um adversário; e um princípio de totalidade - referente à participação no sistema de ação histórica.

Estes elementos permitem uma boa introdução a este assunto central das Ciências Sociais. Para se compreendê-lo no âmbito dos movimentos negros lembramos o importante conceito destinado a melhor compreender as lutas e movimentos pela emancipação negra - o conceito de "negritude".

\section{A Negritude}

Historicamente, o racismo, com seus efeitos e mecanismos de reprodução tem impactado de modo perverso a sociedade brasileira. As mazelas da escravidão se disseminaram, criaram raízes e se transmutaram, a ponto de funcionarem como meio de segregação, em tempos de liberdade, alimentado e disfarçado pelo mito da democracia racial (IPEA, 2014).

A luta da comunidade negra para se fazer representada - eis o cerne da ideia de "negritude" - em um dos espaços que agregue diferentes aspectos de sua cultura, além de oportunizar o lazer é bastante relevante pois, no âmbito deste movimento, as questões discriminatórias e segregadoras são constantes.

Dessa forma, movimentos sociais, na perspectiva de Alain Touraine, dotados de diferentes níveis de identidade, oposição e totalidade constituíram-se em elementos vitais capazes de se apropriar de um espaço urbano com o fim de consolidar um espaço de resistência e desenvolvimento da cultura negra tão prejudicada pelo racismo.

Lembramos que esta importante conquista insere-se no debate atual sobre ações afirmativas de enfrentamento ao racismo uma vez que o movimento pela apropriação do 
Edvaldo Cesar da S. Oliveira, Os Movimentos Sociais para Apropriação e Consolidação do Espaço... Luiz Carlos Soares Santos, João Batista Lopes da Silva e

Luis Otavio T. Assumpção

Memorial Zumbi dos Palmares marca um movimento de responsabilização do Estado, ao incorporar, na agenda governamental, demandas e debates há muito tratados nos encontros com as minorias.

Com lutas, disputas, desafios, articulações foi possível formar espaços de luta, como o Memorial "Zumbi dos Palmares", o que "implicará uma compreensão dos mecanismos políticos, sociais, culturais e educacionais que promovem, em maior ou menor escala em todo o planeta, toda a sorte de preconceitos e discriminações” (LOPES et al., 2009, p. 4).

Muitas discussões têm sido feitas, como mecanismos de luta e valorização da cultura negra. Eis o objetivo principal do espaço Zumbi dos Palmares ao ofertar à comunidade negra (e àqueles que por esta cultura se interessam) os mais diferentes tipos de atividades ligadas a essa temática étnica. Dentre estas, neste trabalho, privilegiamos aquelas relacionadas ao lazer, um direito garantido constitucionalmente, não obstante tantas vezes expropriado.

\section{O Lazer e sua Importância}

Quando falamos em lazer, lembramo-nos de uma legítima preocupação do mundo moderno, desfrutado nos momentos livres das obrigações socialmente determinadas. Direito garantido na Constituição Federal/1988 desempenha papel esencial para disseminaçao, afirmação e difusão da cultura negra no Memorial Zumbi dos Palmares.

Sua importância se legitima em diferentes instâncias, atendendo a diferentes segmentos populacionais. No Art. $1^{\circ}$ da Declaração Universal dos Direitos Humanos, ele é um direito de todos os cidadãos, independentemente do credo, raça, sexo, idade, 
Edvaldo Cesar da S. Oliveira, Os Movimentos Sociais para Apropriação e Consolidação do Espaço... Luiz Carlos Soares Santos, João Batista Lopes da Silva e

Luis Otavio T. Assumpção

classe social e econômica. O Art. 24 o estabelece como um direito de todos. O Art. $6^{\circ}$ do Capítulo II - Dos Direitos Sociais - da Constituição Federal do Brasil (1988), de 14/02/2000, dispõe: "São direitos sociais: a saúde, o trabalho, a moradia, o lazer, a segurança, a previdência social (...)". O Art. 217 trata do desporto, o parágrafo $3^{\circ}$ expõe que "o poder público incentivará o lazer, como forma de promoção social."

A Constituição do Estado do Piauí (1989) em seu Art. 191, Inciso V, fala sobre “a criação ou a preservação de áreas de lazer e de atividades de caráter comunitário”. O Art. 203, parágrafo único, inciso I, enfatiza que o direito à saúde pressupõe condições dignas ao lazer; no Art. 231, o lazer é tido como direito de todos e dever do Estado; no Art. 233, “o poder público incentivará o lazer como forma de promoção social”. O Art. 248 preceitua que é "dever da família, da sociedade e do Estado assegurar à criança e ao adolescente, com absoluta prioridade, o direito ao lazer", entre outros direitos. A Lei Orgânica do Município de Teresina (2011), Art. 231, diz que “o município incentivará o lazer como forma de promoção social.”.

O lazer pode estar a serviço de certos grupos econômicos, que veem nele uma oportunidade de ganhos. Não falta quem tente dirigir o tempo disponível para a busca do lucro, ditado pela "indústria cultural" (BRITO, 2007). No entanto, como mostra este trabalho, as atividades de lazer podem propiciar oportunidades de vivências sociais, culturais, folclóricas, divertimento, repouso e conhecimento sobre a realidade de uma determinada comunidade (MELO, 2010).

Faz-se necessário observar a importância do lazer conforme seu duplo aspecto educativo - educação para e pelo lazer. Neste sentido, não pode ser visto apenas como mecanismo de dissipar tensões cotidianas através do descanso e divertimento (seguramente importantes), mas também como uma atividade de resistência, realização 
Edvaldo Cesar da S. Oliveira, Os Movimentos Sociais para Apropriação e Consolidação do Espaço... Luiz Carlos Soares Santos, João Batista Lopes da Silva e

Luis Otavio T. Assumpção

e crescimento individual e social, considerando a educação no desenvolvimento das pessoas. Trata-se de uma ideia defendida por vários autores (CAMARGO, 2003; MARCELLINO, 2006; DUMAZEDIER, 2008, BRITO, 2007). A estruturação e o uso de espaços e equipamentos de lazer, sua animação por profissionais preparados para esse fim, a ampliação e a diversificação dos conteúdos culturais (PINTO, 2008) constituem eixo fundamental para atender às necessidades da sociedade negra piauiense.

Lazer faz parte do planejamento urbano, com espaços e equipamentos previstos para os diferentes segmentos populacionais, não somente às classes mais favorecidas. Constitucionalmente, devem estar disponíveis para todos independentemente da religião, etnia, credo, condição financeira (MAGNANI, 2003; FERREIRA, 2003; MARCELLINO 2006; FALEIROS, 2006; MASCARENHAS, 2010). No entanto, nem sempre esses espaços/ equipamentos de lazer são ofertados segundo uma lógica de acesso a todos. Tal exclusão obriga os menos favorecidos ou as minorias historicamente construídas - negros, homossexuais, idosos, indígenas, a utilizar espaços que prioritariamente não foram pensados para se desenvolver este fim (DUMAZEDIER, 2008, p.171), obrigando-os a engendrarem movimentos de busca e conquista transformando espaços não pensados prioritariamente para o desenvolvimento do lazer em readaptações e ressignificações para tal fim.

São denominados “equipamentos não específicos de lazer”: espaços construídos para outros fins, mas que em um determinado momento podem vir a servir como equipamentos de lazer (CAMARGO 2003; MARCELLINO, 1987). Destes equipamentos não específicos, os que a sociedade tem mais utilizado são a casa, o bar, a rua, a escola (MARCELLINO, 2006). No caso do espaço Zumbi dos Palmares, antes uma escola, o ambiente é favorável a este propósito, pois elas podem ser apropriadas 
Edvaldo Cesar da S. Oliveira, Os Movimentos Sociais para Apropriação e Consolidação do Espaço... Luiz Carlos Soares Santos, João Batista Lopes da Silva e

Luis Otavio T. Assumpção

como equipamento não específico de lazer, se constituindo em locais propícios. "A comunidade está próxima delas e nos fins de semana e nas férias estão desocupadas" (MARCELLINO, 2006, p.6)

Ou seja, as comunidades minoritárias se veem impelidas a utilizarem os espaços e/ou equipamentos não específicos de lazer como forma de resistência a um sistema sociopolítico que não os trata da mesma maneira. Esses locais que prioritariamente não foram criados para tais fins são transformados e apropriados por falta de uma opção específica e concreta para essa prática.

Embora o direito ao lazer seja preconizado em diferentes legislações e possua status constitucional no Brasil, deixa muito a desejar em relação ao incentivo ao lazer, sobretudo em relação aos mais necessitados. Quando essa "promoção social não se manifesta efetivamente, há uma tendência a ocorrer um aumento das diferenças sociais e um sentimento de revolta nas pessoas menos abastadas" (CAMARGO, 2003, p. 4).

Pensando nisso, levantamos como objetivo geral analisar os movimentos sociais para apropriação e consolidação do espaço de lazer e cultura "Zumbi dos Palmares", localizado em Teresina-PI. Esse trabalho se justifica ao observarmos que na maioria das comunidades que sofrem algum tipo de segregação econômica ou social, desenvolvem-se variadas e múltiplas atividades de lazer em espaços/equipamentos não específicos, configurando um processo de exclusão. Buscamos entender o processo de apropriação de espaços/equipamentos não destinados ao lazer pela comunidade negra neste estudo. 
Edvaldo Cesar da S. Oliveira, Os Movimentos Sociais para Apropriação e Consolidação do Espaço... Luiz Carlos Soares Santos, João Batista Lopes da Silva e

Luis Otavio T. Assumpção

\section{Materiais e Métodos (Metodologia)}

Foi realizada uma pesquisa de natureza qualitativa a fim de aprofundar as questões sociais pertinentes e, por conta disso, atingir um processo mais concreto de investigação. Entendemos que a investigação qualitativa pode apresentar uma visão mais clara das questões referentes à investigação de caráter social, principalmente no tocante às interações e representações sociais.

A investigação foi realizada no Memorial Zumbi dos Palmares, em Teresina-PI e o instrumento utilizado foi a entrevista com roteiro semiestruturado, bastante utilizado nestes estudos de caráter qualitativo. Perguntas abertas possibilitam a análise das falas dos entrevistados e, com isso, são capazes de resgatar a narrativa e a memória dos acontecimentos desenvolvidos e vivenciados.

Também foram analisados documentos referentes ao Projeto de Lei $\mathrm{n}^{\mathrm{0}} 05$, de 12 de março de 2003, encaminhado pelo deputado Olavo Rebelo, que criou o Memorial Zumbi dos Palmares; e o Projeto Político Pedagógico criado por um grupo de professores, técnicos e estudiosos, em junho de 2010, ambos fornecidos pela coordenação do espaço.

As entrevistas foram realizadas com a atual coordenadora, Antonia Aguiar e dois representantes do movimento negro, que participaram da luta, em 2003, como membros do grupo "Coisa de Negro", de representação afrodescendente que iniciaram a luta pela apropriação daquele espaço. Após a criação do memorial, as diferentes entidades representativas que participaram do processo de apropriação elegeram a coordenadora do memorial através do voto do Conselho de Administração, composto por dois representantes das entidades e instituições participantes (órgão Estadual de Cultura; Universidade Federal do Piauí; Universidade Estadual do Piauí; Grupo Afro-cultural 
Edvaldo Cesar da S. Oliveira, Os Movimentos Sociais para Apropriação e Consolidação do Espaço... Luiz Carlos Soares Santos, João Batista Lopes da Silva e

Luis Otavio T. Assumpção

"Coisa de Negro"; "Movimento Negro Unificado"; "Ifaradá" - Núcleo de pesquisa sobre africanidade e afrodescendências; coletivo de mulheres negras "Esperança Garcia”) As respostas foram transcritas e categorizadas para facilitar o entendimento.

\section{Resultado e Discussão}

A primeira categoria de análise se referiu à trajetória histórica da apropriação do espaço. Foi nos relatado que desde a homenagem feita a Domingos Jorge Velho, dando seu nome a escola, houve um descontentamento generalizado entre estudiosos afrodescendentes e não afrodescendentes - ele era responsabilizado pela matança e massacre de negros e índios na região. Esse desconforto tomou corpo na comunidade negra e outros grupos de defesa da cultura negra se juntaram (Grupo Afro-cultural “Coisa de Negro"; "Movimento Negro Unificado", coletivo de mulheres negras “Esperança Garcia”). Pressionaram junto à Secretaria de Educação para que se modificasse o nome da escola; com o apoio da Universidade Estadual do Piauí e da Universidade Federal do Piauí cresceu a pressão.

Em 2003, o Deputado Estadual Olavo Rebelo elaborou o Projeto de Lei para retirar o nome e transferir o espaço para uso da comunidade negra, no mandato do governador Welington Dias, vinculando o espaço, na época, à Secretaria de Cultura e consequente apropriação do mesmo para uso da comunidade negra. Hoje ele é coordenado por uma representante eleita por um Conselho Administrativo (órgão Estadual de Cultura; UFPI; Universidade Estadual do Piauí; Grupo Afro-cultural "Coisa de Negro"; "Movimento Negro Unificado"; "Ifaradá" - Núcleo de pesquisa sobre africanidade e afrodescendências; coletivo de mulheres negras "Esperança Garcia”). 
Edvaldo Cesar da S. Oliveira, Os Movimentos Sociais para Apropriação e Consolidação do Espaço... Luiz Carlos Soares Santos, João Batista Lopes da Silva e

Luis Otavio T. Assumpção

Atualmente tem sido pensada outra mudança do nome - de "Zumbi dos Palmares" para "Esperança Garcia", a primeira mulher escrava negra do Piauí a denunciar maus-tratos sofridos por ela e sua família.

A segunda categoria de análise refere-se às melhorias, lacunas e necessidades relacionadas à oferta de lazer para a comunidade negra após a apropriação do espaço "Zumbi dos Palmares"

A principal dificuldade relatada foi a questão financeira, especialmente pela ausência do CNPJ, o que impossibilita a captação de recursos junto a outros órgãos. Em relação às melhorias, foi destacado seu caráter agregador entre os grupos afro e o crescimento e apoio das representações culturais, permitindo e favorecendo maior visibilidade à cultura negra, especialmente aspectos relacionados à musicalidade, arte, dança, produção de textos, cinema, teatro, com temática negra. Foi também relatado o crescimento e impulso às pesquisas sobre a história da cultura negra. Chamou-nos a atenção ali se constituir um local que o negro pode afirmar sua identidade e suas diferenças com a sociedade, sem medo de ser discriminado ou sofrer represálias.

Ainda sobre a questão financeira, foi destacado o fato de as minorias, muitas vezes, serem preteridas por ocasião da distribuição de recursos, com maior benefício aos mais abastados, em detrimento daqueles em situação de vulnerabilidade social, caso acentuado no âmbito das comunidades negras, "o que tem provocado grande desconforto para muitos e conforto para poucos" (FERREIRA, 2003, p.10).

Também a distribuição dos espaços e equipamentos de lazer tem sido feito de forma desproporcional, privilegiando determinados setores da cidade, em prejuízo de outros, "favorecendo os bairros burgueses e atendendo secundariamente às pressões populares" (FALEIROS, 2006, p. 55). 
Edvaldo Cesar da S. Oliveira, Os Movimentos Sociais para Apropriação e Consolidação do Espaço... Luiz Carlos Soares Santos, João Batista Lopes da Silva e

Luis Otavio T. Assumpção

O espaço, relataram os entrevistados, é realmente de grande importância pois aglutina e organiza os diferentes movimentos negros para discutirem a temática racial e valorizarem sua cultura, transformando-se em ponto de resistência contra o preconceito. Neste sentido, “implicará uma clara compreensão dos mecanismos políticos, sociais, culturais e educacionais que promovem, em maior ou menor escala em todo o planeta, toda a sorte de preconceitos e discriminações (LOPES et al. , 2009, p. 4)”.

Sobre a importância da utilização do espaço pela comunidade negra, a entrevistada respondeu afirmativamente: serve "para desmistificar, resgatar, construir, valorizar e divulgar os aspectos da cultura negra, desenvolver uma consciência da construção de um espaço de difusão da cultura negra dentro da comunidade negra e fora dela. Aqui o negro pode ser reconhecido como tal, sem precisar ficar com medo de ser discriminado, aceitando sua identidade e afirmando a mesma pelo cabelo enrolado, com drede, tranças". Destacou ainda a importância de se mostrar a história do negro no Brasil a partir de sua própria perspectiva e a maneira como foi discriminado e explorado ao longo da sua vida. Trata-se, em sua percepção, de um espaço privilegiado de acolhimento para as diferentes temáticas dos diferentes grupos afros em luta pela causa negra e articulação de ações concretas no sentido de fortalecer suas reivindicações e contribuir para diminuir os preconceitos existentes na cidade de Teresina.

Outro ponto importante observado foi a permanente busca de valorização e difusão da cultura negra, e a necessidade de construção de uma consciência mais clara sobre a mesma, tentando diminuir apelos preconceituosos existentes. Cabe aqui destacar a contribuição do sociólogo Roger Bastide (2001) que tanto estudou a cultura negra no Brasil, ao escrever sobre os espaços religiosos de matriz africana poderem ser vistos 
Edvaldo Cesar da S. Oliveira, Os Movimentos Sociais para Apropriação e Consolidação do Espaço... Luiz Carlos Soares Santos, João Batista Lopes da Silva e

Luis Otavio T. Assumpção

como locais de resistência e conscientização da importância cultural do negro no processo de construção da sociedade brasileira.

Também perguntamos sobre as atividades relevantes e importantes para comunidade negra desenvolvidas no espaço "Zumbi dos Palmares". Foram destacados o papel da biblioteca com temática afro e a disseminação da cultura negra e sua importância; o coral afro de músicas religiosas de matriz africana; da capoeira, do samba de roda, do maculelê; das festas nagô (festas temáticas ao som de afoxé, reggae, hip-hop, os quais agregam diferentes grupos afros existentes em Teresina); a "tela preta" (mostra de cinema com temática racial); cursos de língua/dialeto yorubá; o curso de fotografia com ênfase na identidade, olhares e imagens do movimento negro; o curso sobre técnicas de penteado, tranças, uso de turbantes (muitas vezes o negro não se identifica com seu cabelo em função da maior difusão midiática do cabelo liso).

Um dos objetivos principais destes cursos é justamente valorizar a beleza negra, o cabelo crespo e enrolado; o teatro e as músicas de matriz africana. A dança ganha destaque, em particular por se tratar de importante aspecto da religiosidade africana e, por isso, um importante resgate cultural e simbólico nos terreiros, onde se pode aprender, por exemplo, o afoxé. Neste espaço, estas manifestações se organizam sob a forma de oficinas com intuito de dar visibilidade e empoderamento à cultura negra.

Como base para esse pensamento destacam-se os grupos de luta para afirmação e valorização da cultura negra se utilizarem da religião como ponto unificador. As religiões de matriz africana são, muitas vezes, discriminadas; porém constituem uma das bases dos movimentos negros. 
Edvaldo Cesar da S. Oliveira, Os Movimentos Sociais para Apropriação e Consolidação do Espaço... Luiz Carlos Soares Santos, João Batista Lopes da Silva e

Luis Otavio T. Assumpção

Por exemplo, destaca-se o candomblé, o qual recriava para o negro um mundo no qual ele podia, com certa regularidade, retirar-se da sociedade branca opressiva e dominadora.

O candomblé punha à disposição do negro brasileiro um mundo também negro, comunitário-familiar, justaposto ao mundo branco, de modo que o fiel pudesse passar de um mundo para o outro, como se fossem dimensões ortogonais de uma mesma realidade, em que o não religioso significava a adversidade a que o negro estava sujeito pela realidade histórica da escravidão (BASTIDE, 2001,P 88).

Observamos uma grande preocupação em estimular discussões, debates, reflexões críticas sobre a situação da comunidade negra. Observamos também a oferta de diferentes tipos de lazer - físico, intelectual, social, artístico, manual, gratuitos à comunidade o que demonstra sua grande importância social, especialmente se lembrarmos de que o lazer não é ofertado para todos de maneira igualitária, conforme observaram Ferreira (2003) e Faleiros (2006) em seus estudos. Ou, quando existe a oferta, muitas vezes é vista como uma mercadoria onde as comunidades mais atingidas são as minorias segregadas por gênero, etnia e condição financeira. Assim, a comunidade negra é diretamente atingida, tendo em vista que muitas vezes suas manifestações de lazer são discriminadas.

Outra importante observação sobre as atividades ofertadas refere-se à utilização dos espaços/equipamentos que, apesar de não serem específicos para o desenvolvimento das mesmas, contemplam os objetivos previstos, atendendo a essa comunidade negra, mesmo que ainda timidamente.

\section{Considerações Finais}

Observamos que o processo de apropriação e consolidação do espaço/memorial Zumbi dos Palmares ocorreu de maneira bastante aguerrida, fruto da luta e dos 
Edvaldo Cesar da S. Oliveira, Os Movimentos Sociais para Apropriação e Consolidação do Espaço... Luiz Carlos Soares Santos, João Batista Lopes da Silva e

Luis Otavio T. Assumpção

movimentos históricos contra a secular desvalorização, desconsideração e exclusão da cultura negra e da indignação decorrente da homenagem a um personagem da história conhecido por assassinar índios e negros.

Essa inquietação se concretizou no espaço/memorial Zumbi dos Palmares, que hoje desenvolve importante papel social de resistência e valorização desta cultura ao oferecer atividades de lazer e promover a difusão e valorização da cultura negra no estado do Piauí, mesmo que em um espaço/equipamento não especifico de lazer. O espaço se propõe como objetivo e tarefa de estimular, conscientizar e consolidar, dentro da comunidade em geral, a importância e o valor da etnia negra e, principalmente, da necessidade de valorização da mesma.

Importante ressaltar que a conquista desse espaço consegue apresentar para a sociedade a importância da etnia negra e suas possibilidades criativas em diferentes áreas do conhecimento desenvolvidas nas oficinas e oferecidas no local, mostrando o grande potencial dessa comunidade e, principalmente, se apresentando como um farol de combate às atitudes preconceituosas e discriminatórias sofridas pelos negros ao longo da história.

\section{REFERÊNCIAS}

BASTIDE, R. O candomblé da Bahia: rito nagô. 3. ed. Tradução de Le candomblé de Bahia, de 1958. São Paulo: Nacional, 1978. Nova edição: São Paulo, Companhia das Letras, 2001.400 p.

BLUMER, Herbert. Movimentos sociais. In: PEREIRA, Luiz. Subdesenvolvimento e desenvolvimento. Rio de janeiro: Zahar, 1976.p 81-92.

BOBBIO, Norberto. Dicionário de política. 11. ed. Brasília: Universidade de Brasília, $1998.674 \mathrm{p}$.

BRASIL, Decreto Lei $\mathbf{n}^{0} \mathbf{5 . 3 1 1}$ de 12 de março de 2003. Assembleia Legislativa, Teresina, Piaú, 12 de março 2003. P.230-231. 
Edvaldo Cesar da S. Oliveira, Os Movimentos Sociais para Apropriação e Consolidação do Espaço... Luiz Carlos Soares Santos, João Batista Lopes da Silva e

Luis Otavio T. Assumpção

. Projeto Político Pedagógica do memorial Zumbi dos Palmares. Piauí: Secretaria de Cultura do Estado do Piauí (SECULT), 2010.

. Constituição (1988). Constituição da República Federativa do Brasil, 1998. Brasília: Senado Federal, Centro Gráfico, 1988. 292p.

. Constituição (1989). Constituição da República Federativa do Piauí. Piauí: Assembleia, Centro Gráfico, 1989. 280p.

Proposta pedagógica do memorial Zumbi dos Palmares. Piauí: Secretaria de Cultura do Estado do Piauí (SECULT), 2003.

BRASIL. Situação social da população negra por estado. Brasília: Secretaria de Políticas de Promoção da Igualdade Racial, IPEA, 2014.115 p.

BRITO. Gustavo André Pereira de. Formação e qualificação para atuação profissional em lazer: o caso da política pública de Piracicaba. 2007.157f dissertação (Mestrado)-Universidade Metodista de Piracicaba (UNIMEP), Piracicaba, 2007.

CAMARGO, Luiz Otávio de Lima. O que é lazer. São Paulo: Brasiliense, 2003. 50p.

DAWSON E GETTYS. Introdução a sociology. São Paulo: Editora da Universidade Estadual de Campinas, 1989. p. 230.

DUMAZEDIER, Joffre. Sociologia empírica do lazer. 3. ed. São Paulo: Perspectiva, 2008.124p.

FALEIROS, Vicente de Paula. O que é política social. 5. ed. São Paulo: Brasiliense, 2006.84p.

FERREIRA, Adriana dos Reis. A Compreensão do lazer no planejamento urbano de Goiânia: aproximações históricas. 2003.160f. Dissertação (mestrado)-Universidade Estadual de São Paulo, Campinas, 2003.

GOHN, Maria G. Movimentos sociais e redes de mobilizações civis no Brasil contemporâneo. Petrópolis: Vozes, 2010.188p.

LOPES, Jose de Sousa Miguel; REIS, Maria das Dores; MACHADO, Maurimar Melo Santos Costa. O preconceito no contexto educacional, MG: Unileste, 2009.

MAGNANI, José Guilherme Cantor. Festa no pedaço: cultura popular e lazer na cidade. 3. ed. São Paulo: Hucitec/Unesp, 2003.168p.

MARCELLINO, Nelson Carvalho. Estudos do lazer: uma introdução. 4. ed. Campinas: Autores Associados, 2006.112p.

Lazer e educação. Campinas: Papirus, 1987.164p. 
Edvaldo Cesar da S. Oliveira, Os Movimentos Sociais para Apropriação e Consolidação do Espaço... Luiz Carlos Soares Santos, João Batista Lopes da Silva e

Luis Otavio T. Assumpção

MASCARENHAS, Gilmar. Contribuições da geografia para o estudo do lazer. In: MELO, Victor Andrade de. (Org.). Lazer: olhares multidisciplinares. Campinas: Alínea, 2010. Capítulo 08, p.140-51.

MELO, Victor Andrade de. Contribuições da história para o estudo do lazer. In: MELO, Victor Andrade de (Org.). Lazer: olhares multidisciplinares. Campinas: Alínea, 2010. Capítulo 01, p.16.-38.

MORRIS, Aldon. Reflections on Social Movement Theory: Criticisms and Proposals. In: Contemporary Sociology, v. 29, p. 115-454, 2000.

PIAUÍ. Constituição (1989). Constituição do Estado do Piauí. Disponível em: http://www.camara.gov.br/interacao/constituicoes/constituicão_piauí.pdf. Acesso em: 03 ago. 2015.

PICOLOTTO, Everton Lazzaretti. Processos de diferenciação dos movimentos sociais do campo no sul do Brasil: identidade, articulação política e projeto, Campina Grande, Raízes, v. 26, n. 1 e 2, jan./dez., p. 46-58, 2007.

PINTO, Leila Mirtes Santos de Magalhães. Políticas públicas de lazer. In: MARCELLINO, Nelson Carvalho (Org.). Políticas públicas de lazer. Campinas: Alínea, Capítulo 5, p. 90, 2008.

TERESINA. Lei Orgânica do Município de Teresina (2011). Disponível em: http://www.camarateresina.pi.gov.br. Acesso em: 03 ago. 2015.

TOURAINE, Alain. Os movimentos sociais. In: FORACCHI, M. M.; MARTINS, J. de S. Sociologia e sociedade. Rio de Janeiro: Livros Técnicos e Científicos Editora, 1977.p.30-45.

\section{Endereço dos Autores:}

Edvaldo Cesar da S. Oliveira

Rua Gabriel Ferreira 371 Centro

Teresina - PI - 64.001-250

Endereço Eletrônico: edvaldooliveira32@hotmail.com

Luiz Carlos Soares Santos

Rua José Omatti, 3313 Apto:201 Bl: A

Condomínio Ilhotas - Bairro Ilhotas

Teresina - PI -64.015-050

Endereço Eletrônico: luizcarlossax@hotmail.com

João Batista Lopes da Silva

Rua dos Mognos, 412 A6 Residencial Village,

Caixa Postal 736 
Edvaldo Cesar da S. Oliveira, Os Movimentos Sociais para Apropriação e Consolidação do Espaço... Luiz Carlos Soares Santos, João Batista Lopes da Silva e

Luis Otavio T. Assumpção

Sinop - MT - 78.555-283

Endereço Eletrônico:jb@unemat.br

Luis Otavio T. Assumpção

QS 07 - Lote 01 - EPCT - Taguatinga

Brasília - DF - 71.966-700

Endereço Eletrônico: luiso@ucb.br 